\title{
New Developments in Sleep Research: Molecular Genetics, Gene Expression, and Systems Neurobiology
}

\author{
Thomas S. Kilduff, ${ }^{1}$ Ed S. Lein, ${ }^{2}$ Horacio de la Iglesia, ${ }^{3}$ Takeshi Sakurai, ${ }^{4}$ Ying-hui Fu, ${ }^{5}$ and Paul Shaw ${ }^{6}$ \\ ${ }^{1}$ Biosciences Division, SRI International, Menlo Park, California 94025, ${ }^{2}$ Department of Neuroscience, Allen Institute for Brain Science, Seattle, Washington \\ 98103, ${ }^{3}$ Department of Biology, University of Washington, Seattle, Washington 98195-1800, ${ }^{4}$ Department of Molecular Neuroscience and Integrative \\ Physiology, Kanazawa University, Kanazawa 920-8640, Japan, ${ }^{5}$ Department of Neurology, University of California San Francisco School of Medicine, San \\ Francisco, California 94158-2324, and ${ }^{6}$ Department of Anatomy and Neurobiology, Washington University School of Medicine, St. Louis, Missouri 63110
}

Understanding the mechanisms that underlie the control of sleep and wakefulness is a major research area in neuroscience. This mini-symposium review highlights some recent developments at the gene, molecular, cellular, and systems levels that have advanced this field. The studies discussed below use organisms ranging from flies to humans and focus on the interaction between the sleep homeostatic and circadian systems, the consequences of mutations in genes involved in the circadian clock on sleep timing, the effects of sleep deprivation on brain gene expression, the discovery of "sleep active" neurons in the cerebral cortex, the role of the hypocretin/orexin system in the maintenance of sleep and wakefulness, and the interaction between sleep and learning.

Key words: homeostatic system; circadian system; sleep timing; sleep deprivation; hypocretin/orexin system; sleep and learning

\section{Introduction}

Sleep research is a field that is undergoing a rapid transition. The "modern" era of sleep research can be dated from the discovery of the periodic occurrence of rapid eye movements during sleep (Aserinsky and Kleitman, 1953). It was soon recognized that sleep was not a unitary phenomenon but, instead, involved a cyclic alternation between periods of "deep" sleep characterized by large-amplitude, slow waves recorded in the electroencephalogram (slow-wave sleep) and periods of a desynchronized cortical activity accompanied by reduced muscle tone and rapid eye movements (REM sleep). The founders of the field quickly recognized the clinical significance of sleep and the existence of sleep disorders. With the founding of the first sleep disorders clinic in 1970 at Stanford University School of Medicine, much of the emphasis of the field shifted from identification of the neural pathways and mechanisms underlying the sleep/wake cycle to the onerous but eventually highly successful task of establishing the field of sleep disorders medicine (Shepard et al., 2005).

As the clinical discipline of sleep prospered, sleep neurobiology through the 1990s focused primarily on mammals and used systems physiological and pharmacological approaches. Meanwhile, the related field of circadian rhythms - which had its origins in biology rather than psychology and psychiatry-em-

Received Aug. 10, 2008; revised Sept. 10, 2008; accepted Sept. 10, 2008

This work supported by National Institutes of Health Grants R01AG020584, R01HL059596, R01HL059658, R01MH061755, R01MH075016, P50MH074924, and NS051305, United States Army Medical Research Acquisition Activity Award W81XWH-06-1-0131, and the Ministry of Education, Culture, Sports, Science and Technology of Japan. We are grateful to Dr. Jonathan Wisor for his constructive comments on this manuscript.

Address correspondence to Dr. Thomas S. Kilduff, Biosciences Division, SRI International, Menlo Park, CA 94025. E-mail: thomas.kilduff@sri.com.

DOI:10.1523/JNEUROSCI.3768-08.2008

Copyright $\odot 2008$ Society for Neuroscience $\quad$ 0270-6474/08/2811814-05\$15.00/0 braced comparative approaches and a mindset that facilitated use of molecular genetics, ultimately leading to the isolation of numerous "clock" genes in flies, rodents, and humans. A seminal event that changed the sleep field was the determination in 1999 that mutations that affected the hypocretin/orexin system, a neuropeptidergic system that had only been described the previous year (de Lecea et al., 1998; Sakurai et al., 1998), could result in the sleep disorder narcolepsy in both canine (Lin et al., 1999) and murine (Chemelli et al., 1999) models. These twin discoveries led to the demonstration just 12 months later that human narcolepsy is likely a neurodegenerative disease in which the hypocretin/ orexin neurons are lost (Peyron et al., 2000; Thannickal et al., 2000).

Since 2000, sleep research has taken on a different flavor. Comparative studies using flies, fish, worms, and nontraditional mammalian systems have been embraced. Sleep studies of genetically manipulated animals have become routine. Use of microarrays to assess gene expression has become widespread. The number of molecular genetic studies of sleep disorders is on the rise. At the same time, the traditional systems neurobiology vein within sleep research has become even stronger as the circuitry that underlies normal and pathophysiological sleep continues to be revealed and new models advanced (e.g., Saper et al., 2001) and new techniques introduced (Adamantidis et al., 2007). These developments have caused a renewed appreciation within the field that sleep, by its very nature, requires a multidisciplinary translational approach to achieve understanding. The irony is that, since the prescient founding of the first sleep disorders clinic, sleep has been a field in which translational medicine has always been practiced. The mini-symposium described below presents some of the current directions in sleep research, involving experimental approaches at the genetic, molecular, cellular, and systems neurobiology levels. 
Local, behavioral state-specific changes in gene expression revealed by DNA microarrays and high-throughput in situ hybridization (E. S. Lein)

A number of studies have described the molecular correlates of sleeping and waking states as a means to understand the biological necessity for sleep and the consequences of sleep deprivation (SD). The majority of these studies have used immediate early gene (IEG) expression to identify brain regions selectively activated during sleep, wakefulness, and SD (O'Hara et al., 1993; Cirelli et al., 1995; Pompeiano et al., 1995; Terao et al., 2003b) and, more recently, microarrays to identify broader sets of genes with state-dependent expression (Cirelli and Tononi, 2000; Terao et al., 2003a, 2006; Cirelli et al., 2004, 2006; Mackiewicz et al., 2007). Building on this work, Lein and colleagues have undertaken a large-scale effort to identify and map cellular-level expression patterns of genes displaying state-dependent gene expression. This approach involved anatomical mapping of IEG expression across sleeping, waking, and SD behavioral conditions, and laser capture/ microarray analysis of subdivisions of the neocortex, hippocampal formation, and amygdala that show consistent IEG induction during SD. Using a high-throughput in situ hybridization (ISH) platform (Lein et al., 2007), a cohort of candidate genes predicted to show state-dependent expression was then examined across these behavioral conditions to assess cellular resolution changes in gene expression across the entire brain.

Analysis of microarray data has provided evidence for diurnal, state-dependent (e.g., waking), and state-specific (e.g., $\mathrm{SD})$ gene regulation that vary across different structures. Consistent with previous work (Terao et al., 2003b; Cirelli et al., 2004), IEG expression is generally higher in waking than sleeping and is further induced after SD. With a few exceptions, IEGs as a class show consistent anatomical distributions and provide a coherent picture of brain regions differentially activated during waking and SD relative to sleeping. IEG induction in the cerebral cortex is nearly exclusively in excitatory neurons, and different IEGs label partially overlapping subsets of neurons after SD. Many candidate genes identified in the study are generally characteristic of activity-regulated genes and are induced during waking and SD in the same regions as IEGs with which they show overlapping cellular distributions. However, individual genes show either more widespread SD induction than IEGs or, as in the case of the circadian deadenylase nocturnin (ccrn4l) (Green and Besharse, 1996), much more anatomically restricted induction. Evidence was also obtained for circadian and SD-induced glial gene expression. Overall, ISH analysis of the entire gene set demonstrates complex anatomical, circadian, and state-dependent gene regulation. These data have been made available as a publicly accessible data resource (http://sleep.alleninstitute.org).

\section{Unmasking properties of the sleep/wake cycle in an animal model of circadian desynchronization (H. O. de la Iglesia)}

Sleep and wake represent the most dramatic alternation of behavioral physiological states. In most animals, sleep usually occurs at a specific time of the day, with nocturnal animals sleeping during the day and diurnal animals during the night. The daily phase and consolidation of sleep relies on two regulatory processes. Sleep propensity depends on both a homeostatic increase of sleep debt during waking ("process S") and on regulation by the circadian clock ("process C") that increases sleep propensity at specific times of the day. This dual regulation by the sleep homeostat and by the circadian system is not limited to the mere gating of sleep and wakefulness but also has a direct consequence on sleep architecture. Sleep in humans is typically constituted by $\sim 90$ min cycles of alternating non-rapid eye movement (NREM) and REM sleep; as the sleep bout progresses, the duration of stages 3 and 4 of NREM becomes relatively shorter and REM bouts become relatively longer within each cycle. Forced desynchrony protocols, in which human subjects are scheduled to rest-activity cycles different from $24 \mathrm{~h}$ and close to the limits of entrainment of the circadian system, have demonstrated the interplay between homeostatic and circadian regulation of sleep stages. Under these circumstances, the overall sleep-wake cycle adjusts to the rest-activity cycle, yet specific sleep stages show different levels of adjustment (Dijk and Czeisler, 1995; Czeisler and Dijk, 2001). Whereas slow-wave sleep (which characterizes NREM stages 3 and 4) remains synchronized with the sleep episodes, REM propensity is not linked to scheduled sleep time but rather free-runs with a circadian period and a phase coincident with the nadir of core body temperature. The role of the master circadian clock located within the suprachiasmatic nucleus (SCN) in the regulation of sleep has been clearly established (Mistlberger, 2005), yet its role in the regulation of specific sleep stages remains to be determined. The de la Iglesia laboratory has developed a rat model of circadian forced desynchrony that exhibits all of the key features of forced desynchronized human subjects, including the desynchronization of sleep stages (de la Iglesia et al., 2004; Cambras et al., 2007). The desynchronization of sleep stages in these animals is associated with the independent clock gene expression within subregions of the SCN. Together, these data suggest that the SCN is involved not only in regulating the circadian gating of sleep and wakefulness, but also the circadian gating of specific sleep stages. Furthermore, specific subregions of the SCN may be involved in the regulation of specific sleep stages.

\section{Acute and chronic regulation of sleep/wakefulness states by orexin/hypocretin (T. Sakurai)}

Sleep and wakefulness are regulated to occur at appropriate times in accordance with our internal and external environments. Life-essential activities, such as avoiding danger and finding food, are regulated by factors such as emotion, reward, and energy balance that both require and affect vigilance and wakefulness (Sakurai, 2007). Recent findings on input and output systems of orexin (hypocretin) neurons indicate that these neurons are involved in sensing the body's external and internal environments as well as regulating the states of sleep and wakefulness, which are beneficial for survival. The importance of orexins in the maintenance of consolidated sleep/ wake states is demonstrated by the fact that the sleep disorder narcolepsy is caused by orexin deficiency in human and animals (Peyron et al., 2000; Thannickal et al., 2000). These peptides activate wake-active monoaminergic and cholinergic neurons in the hypothalamus and brainstem to maintain long periods of wakefulness. Orexin neurons are exclusively localized within the tuberal and lateral hypothalamus and project to numerous brain regions. Especially strong innervation by orexin-immunoreactive fibers was observed in the locus ceruleus, dorsal raphe nuclei, tuberomammillary nuclei, and lateral dorsal tegmental and pedunculopontine nuclei (Peyron et al., 1998), suggesting that orexin neurons affect the activity of these nuclei to regulate sleep/wakefulness states. 
Orexin neurons receive abundant input from the limbic system, which might be important for maintaining alertness during emotional situations. Orexin neurons are regulated by peripheral metabolic cues, including ghrelin, leptin, and glucose, suggesting that these neurons might provide a link between energy homeostasis and vigilance states (Yamanaka et al., 2003). Furthermore, these neurons are inhibited by sleepactive GABAergic neurons in the ventrolateral preoptic area (VLPO), regulation that might be important for maintenance of sleep. Orexin neurons are also known to be regulated by local GABAergic interneurons. To probe the physiological importance of this GABAergic regulation of orexin neurons, we analyzed the in vivo and in vitro phenotype of mice lacking the $G A B A_{B 1}$ gene specifically in orexin neurons $\left(G A B A_{B 1}{ }^{\text {flox/flox; }}\right.$; orexin-Cre mice) and found that $\mathrm{GABA}_{\mathrm{B}}$ receptors on orexin neurons are essential for stabilizing and consolidating sleep/ wake states. In $G A B A_{B 1}{ }^{\text {flox/flox }}$; orexin-Cre brain slices, the absence of $G_{A B A}$ receptors decreases the sensitivity of orexin neurons to both excitatory and inhibitory inputs resulting from augmented $\mathrm{GABA}_{\mathrm{A}}$-mediated inhibition, which increases the membrane conductance and shunts postsynaptic currents in these neurons. $G A B A_{B 1}{ }^{\text {flox/flox }}$; orexin-Cre mice exhibit severe fragmentation of sleep/wake states during both the light and dark periods without showing an abnormality in total sleep time or signs of cataplexy. Thus, $\mathrm{GABA}_{\mathrm{B}}$ receptors on orexin neurons are crucial in the appropriate control of orexinergic tone and sleep/wake states.

\section{Identification of a population of sleep-active cerebral cortex neurons (T. S. Kilduff)}

As indicated above, the timing and the amount of sleep are thought to be caused by an interaction between a circadian process (process C) and a sleep-related homeostatic process (process S). When this "two process model of homeostatic sleep regulation" was proposed by Borbely in 1982, process C was known to be regulated by the SCN, but the anatomical basis of process $S$ has since remained elusive. Although "sleepactive" neurons have been found in the VLPO and the median preoptic areas, curiously, sleep-active neurons are yet to be described in the cerebral cortex despite the fact that the intensity of slow wave activity (SWA) in the electroencephalogram increases during NREM sleep in proportion to previous wake duration. Using Fos expression as a functional marker in conjunction with immunolabeling for phenotypic markers to identify specific neuronal populations, we recently identified a population of cells in the cerebral cortex that is activated during sleep in three mammalian species (Gerashchenko et al., 2008). These cortical neurons are the smallest currently known subset of GABAergic interneurons and express neuronal nitric oxide synthase (nNOS). nNOS neurons are unique among GABAergic neurons in that they project both intraand interhemispherically. Fos expression in "sleep-active" nNOS-immunoreactive neurons is highly correlated with NREM $\delta$ energy, a measure closely related to SWA. "Sleepactive" nNOS neurons are innervated by serotonin and acetylcholine, neurotransmitter systems that have long been implicated in sleep/wake control. Although Fos expression has been found to correspond well with the patterns of neuronal firing during sleep and wakefulness in the hypothalamus and brainstem, cellular electrophysiological studies will be needed to determine the firing pattern of cortical nNOS neurons across behavioral states. Nonetheless, cortical nNOS- immunoreactive neurons may be part of the neurobiological substrate that underlies homeostatic sleep regulation.

Molecular characterization of human sleep variants (Y.-h. Fu) Sleep duration and disruption have a significant impact on human health, quality of life, and life expectancy. Among humans, it is clear that the biological need for sleep varies dramatically. Natural short sleepers have a lifelong tendency to sleep only $4-5 \mathrm{~h}$ per night and to awaken refreshed and energetic. Natural long sleepers biologically require $9-10 \mathrm{~h} /$ night to feel well rested. The reason for these physiological differences is unknown and the genetic basis has not been explored.

Although relatively little is known regarding the genetic basis of sleep, there is a wealth of information on the genetics of circadian clock function across species. Sleep and circadian function are distinct processes that interact in living organisms. Although these two systems can operate independently, recent studies indicate a more intimate relationship.

Over the last decade, genetic material has been collected from individuals and families with circadian rhythm disturbances including familial advanced sleep phase syndrome (FASPS) and familial delayed sleep phase syndrome. To date, two genetic causes of FASPS have been reported. The first described cause is a mutation in hPER2, a homolog of the fly gene that was the first gene determined to be necessary for proper circadian rhythmicity (Toh et al., 2001). This mutation occurs in a region that is important for the suppressor function of the PER2 protein in the core molecular clock (Xu et al., 2007). The second known cause is a mutation in a gene encoding a protein kinase called casein kinase I $\delta(C K I \delta)$ (Xu et al., 2005). CKI $\delta$ is also a human homolog of fly and hamster genes known to be critical for proper circadian function. Transgenic mice harboring the human mutation also have a circadian phenotype. This mutation leads to a lowered enzymatic activity which then causes the circadian phenotype. Recently, we have identified a mutation in another transcriptional suppressor of the molecular clock that leads to a natural short sleep phenotype in humans. This discovery represents a new opportunity for us to begin to probe the mechanisms of sleep homeostasis in humans.

Despite the exciting developments in the last decade on the neuronal pathways involved in wakefulness, sleep induction/ maintenance, and molecular characterization of the circadian clock, the mechanism that controls how much sleep we need is entirely unknown. A dramatic change in medical research and an explosion in our understanding of many human diseases has occurred since the early 1990s that is largely attributable to advances in the field of human genetics. Human genetics has proven a very effective tool to help identify the key players in biological or disease pathways. This approach to the identification of genes that are important in human behavioral phenotypes was fruitful in FASPS. The prospect of identification of mutations that give rise to alterations in daily sleep requirement represents a unique opportunity to delve into the molecular regulatory mechanisms of sleep homeostasis.

\section{Molecular dissection of sleep and learning in Drosophila (P. Shaw)}

Extended wakefulness disrupts acquisition of short-term memories in mammals (Harrison et al., 2000; Rogers et al., 2003). However, the underlying molecular mechanisms triggered by extended waking and restored by sleep are unknown. Moreover, the neuronal circuits that depend on sleep for optimal learning remain unidentified. Using Drosophila as an experimental organ- 
ism, we evaluated learning using the aversive phototaxic suppression test (Le Bourg and Buecher, 2002). In this task, flies learn to avoid light that is paired with an aversive stimulus (quinine and humidity). We found an extensive homology in the sleep deprivation-induced learning impairment between flies and humans (Seugnet et al., 2008). Both $6 \mathrm{~h}$ and $12 \mathrm{~h}$ of SD are sufficient to impair learning in Canton-S (Cs) flies. Moreover, learning is impaired at the end of the normal waking day in direct correlation with time spent awake. Mechanistic studies indicate that this task requires that the mushroom bodies (MBs) of the fly brain be intact and that the dopamine D1-like receptor ( $D D A 1)$ is functional. Importantly, SD-induced learning impairments can be rescued by targeted gene expression of the $d D A 1$ receptor to the MBs. These data provide direct evidence that extended wakefulness disrupts learning in Drosophila. These results demonstrate that it is possible to prevent the effects of SD by targeting a single neuronal structure and to identify the cellular and molecular targets adversely affected by extended waking in a genetically tractable model organism.

\section{Conclusion}

The presentations in the mini-symposium summarized above highlight only a few of the new directions in sleep research. Some of the many exciting areas that are omitted include imaging of brain activity during sleep, the relationship between sleep and learning in humans, the interaction between sleep deprivation, cognition, and performance, and the rapidly expanding area of pharmacogenetics that will likely lead to the development of new sleep- and wake-promoting medications. With increased international travel and pressure for 24/7 operations, as well as changing demographics resulting in increased age-related sleep disorders, the demand for understanding of the neurobiology underlying sleep and wakefulness has never been greater.

\section{References}

Adamantidis AR, Zhang F, Aravanis AM, Deisseroth K, de Lecea L (2007) Neural substrates of awakening probed with optogenetic control of hypocretin neurons. Nature 450:420-424.

Aserinsky E, Kleitman N (1953) Regularly occurring periods of eye motility, and concomitant phenomena, during sleep. Science 118:273-274.

Cambras T, Weller JR, Anglès-Pujoràs M, Lee ML, Christopher A, DíezNoguera A, Krueger JM, de la Iglesia HO (2007) Circadian desynchronization of core body temperature and sleep stages in the rat. Proc Natl Acad Sci USA 104:7634-7639.

Chemelli RM, Willie JT, Sinton CM, Elmquist JK, Scammell T, Lee C, Richardson JA, Williams SC, Xiong Y, Kisanuki Y, Fitch TE, Nakazato M, Hammer RE, Saper CB, Yanagisawa M (1999) Narcolepsy in orexin knockout mice: molecular genetics of sleep regulation. Cell 98:437-451.

Cirelli C, Tononi G (2000) Gene expression in the brain across the sleepwaking cycle(1). Brain Res 885:303-321.

Cirelli C, Pompeiano M, Tononi G (1995) Sleep deprivation and c-fos expression in the rat brain. J Sleep Res 4:92-106.

Cirelli C, Gutierrez CM, Tononi G (2004) Extensive and divergent effects of sleep and wakefulness on brain gene expression. Neuron 41:35-43.

Cirelli C, Faraguna U, Tononi G (2006) Changes in brain gene expression after long-term sleep deprivation. J Neurochem 98:1632-1645.

Czeisler CA, Dijk DJ (2001) Human circadian physiology and sleep-wake regulation. In: Handbook of behavioral neurobiology: circadian clocks (Takahashi JS, Turek FW, Moore RY, eds), pp 531-569. New York: Kluwer Academic/Plenum.

de la Iglesia HO, Cambras T, Schwartz WJ, Díez-Noguera A (2004) Forced desynchronization of dual circadian oscillators within the rat suprachiasmatic nucleus. Curr Biol 14:796-800.

de Lecea L, Kilduff TS, Peyron C, Gao X, Foye PE, Danielson PE, Fukuhara C, Battenberg EL, Gautvik VT, Bartlett FS 2nd, Frankel WN, van den Pol AN, Bloom FE, Gautvik KM, Sutcliffe JG (1998) The hypocretins: hypothalamus-specific peptides with neuroexcitatory activity. Proc Natl Acad Sci U S A 95:322-327.

Dijk DJ, Czeisler CA (1995) Contribution of the circadian pacemaker and the sleep homeostat to sleep propensity, sleep structure, electroencephalographic slow waves, and sleep spindle activity in humans. J Neurosci 15:3526-3538.

Gerashchenko D, Wisor JP, Burns D, Reh RK, Shiromani PJ, Sakurai T, de la Iglesia HO, Kilduff TS (2008) Identification of a population of sleepactive cerebral cortex neurons. Proc Natl Acad Sci USA 105:10227-10232.

Green CB, Besharse JC (1996) Identification of a novel vertebrate circadian clock-regulated gene encoding the protein nocturnin. Proc Natl Acad Sci U S A 93:14884-14888.

Harrison Y, Horne JA, Rothwell A (2000) Prefrontal neuropsychological effects of sleep deprivation in young adults-a model for healthy aging? Sleep 23:1067-1073.

Le Bourg E, Buecher C (2002) Learned suppression of photopositive tendencies in Drosophila melanogaster. Anim Learn Behav 30:330-341.

Lein ES, Hawrylycz MJ, Ao N, Ayres M, Bensinger A, Bernard A, Boe AF, Boguski MS, Brockway KS, Byrnes EJ, Chen L, Chen L, Chen TM, Chin MC, Chong J, Crook BE, Czaplinska A, Dang CN, Datta S, Dee NR, et al. (2007) Genome-wide atlas of gene expression in the adult mouse brain. Nature 445:168-176.

Lin L, Faraco J, Li R, Kadotani H, Rogers W, Lin X, Qiu X, de Jong PJ, Nishino S, Mignot E (1999) The sleep disorder canine narcolepsy is caused by a mutation in the hypocretin (orexin) receptor 2 gene. Cell 98:365-376.

Mackiewicz M, Shockley KR, Romer MA, Galante RJ, Zimmerman JE, Naidoo N, Baldwin DA, Jensen ST, Churchill GA, Pack AI (2007) Macromolecule biosynthesis-a key function of sleep. Physiol Genomics 31:441-457.

Mistlberger RE (2005) Circadian regulation of sleep in mammals: role of the suprachiasmatic nucleus. Brain Res Brain Res Rev 49:429-454.

O'Hara BF, Young KA, Watson FL, Heller HC, Kilduff TS (1993) Immediate early gene expression in brain during sleep deprivation: preliminary observations. Sleep 16:1-7.

Peyron C, Tighe DK, van den Pol AN, de Lecea L, Heller HC, Sutcliffe JG, Kilduff TS (1998) Neurons containing hypocretin (orexin) project to multiple neuronal systems. J Neurosci 18:9996-10015.

Peyron C, Faraco J, Rogers W, Ripley B, Overeem S, Charnay Y, Nevsimalova S, Aldrich M, Reynolds D, Albin R, Li R, Hungs M, Pedrazzoli M, Padigaru M, Kucherlapati M, Fan J, Maki R, Lammers GJ, Bouras C, Kucherlapati R, et al. (2000) A mutation in a case of early onset narcolepsy and a generalized absence of hypocretin peptides in human narcoleptic brains. Nat Med 6:991-997.

Pompeiano M, Cirelli C, Arrighi P, Tononi G (1995) c-Fos expression during wakefulness and sleep. Neurophysiol Clin 25:329-341.

Rogers NL, Dorrian J, Dinges DF (2003) Sleep, waking and neurobehavioural performance. Front Biosci 8:s1056-1067.

Sakurai T (2007) The neural circuit of orexin (hypocretin): maintaining sleep and wakefulness. Nat Rev Neurosci 8:171-181.

Sakurai T, Amemiya A, Ishii M, Matsuzaki I, Chemelli RM, Tanaka H, Williams SC, Richardson JA, Kozlowski GP, Wilson S, Arch JR, Buckingham RE, Haynes AC, Carr SA, Annan RS, McNulty DE, Liu WS, Terrett JA, Elshourbagy NA, Bergsma DJ, et al. (1998) Orexins and orexin receptors: a family of hypothalamic neuropeptides and $G$ protein-coupled receptors that regulate feeding behavior. Cell 92:573-585.

Saper CB, Chou TC, Scammell TE (2001) The sleep switch: hypothalamic control of sleep and wakefulness. Trends Neurosci 24:726-731.

Seugnet L, Suzuki Y, Vine L, Gottschalk L, Shaw PJ (2008) D1 receptor activation in the mushroom bodies rescues sleep-loss-induced learning impairments in Drosophila. Curr Biol 18:1110-1117.

Shepard JW Jr, Buysse DJ, Chesson AL Jr, Dement WC, Goldberg R, Guilleminault C, Harris CD, Iber C, Mignot E, Mitler MM, Moore KE, Phillips BA, Quan SF, Rosenberg RS, Roth T, Schmidt HS, Silber MH, Walsh JK, White DP (2005) History of the development of sleep medicine in the United States. J Clin Sleep Med 1:61-82.

Terao A, Steininger TL, Hyder K, Apte-Deshpande A, Ding J, Rishipathak D, Davis RW, Heller HC, Kilduff TS (2003a) Differential increase in the 
expression of heat shock protein family members during sleep deprivation and during sleep. Neuroscience 116:187-200.

Terao A, Greco MA, Davis RW, Heller HC, Kilduff TS (2003b) Regionspecific changes in immediate early gene expression in response to sleep deprivation and recovery sleep in the mouse brain. Neuroscience 120:1115-1124.

Terao A, Wisor JP, Peyron C, Apte-Deshpande A, Wurts SW, Edgar DM, Kilduff TS (2006) Gene expression in the rat brain during sleep deprivation and recovery sleep: an Affymetrix GeneChip study. Neuroscience 137:593-605.

Thannickal TC, Moore RY, Nienhuis R, Ramanathan L, Gulyani S, Aldrich M, Cornford M, Siegel JM (2000) Reduced number of hypocretin neurons in human narcolepsy. Neuron 27:469-474.

Toh KL, Jones CR, He Y, Eide EJ, Hinz WA, Virshup DM, Ptácek LJ, Fu YH
(2001) An hPer2 phosphorylation site mutation in familial advanced sleep phase syndrome. Science 291:1040-1043.

Xu Y, Padiath QS, Shapiro RE, Jones CR, Wu SC, Saigoh N, Saigoh K, Ptácek LJ, Fu YH (2005) Functional consequences of a CKIdelta mutation causing familial advanced sleep phase syndrome. Nature 434:640-644.

Xu Y, Toh KL, Jones CR, Shin JY, Fu YH, Ptácek LJ (2007) Modeling of a human circadian mutation yields insights into clock regulation by PER2. Cell 128:59-70.

Yamanaka A, Beuckmann CT, Willie JT, Hara J, Tsujino N, Mieda M, Tominaga M, Yagami K, Sugiyama F, Goto K, Yanagisawa M, Sakurai T (2003) Hypothalamic orexin neurons regulate arousal according to energy balance in mice. Neuron 38:701-713. 